\title{
A CONDIÇÃO FEMININA EM O MULATO, DE ALUÍSIO AZEVEDO
}

\author{
Emilia Tainá dos Santos Rocha ${ }^{1}$ \\ Taleessa Regina Silva Cavalcante ${ }^{2}$ \\ Adriana Aguiar ${ }^{3}$
}

RESUMO: O presente artigo tem como objetivo analisar a condição feminina na obra $O$ mulato, de Aluísio Azevedo. Optou-se pelo levantamento bibliográfico de obras com abordagem histórica, com ênfase nas concepções teóricas da brasileira Mary Del Priore e da indiana Gayatri Spivak, para refletir sobre o tratamento e a condição das mulheres no Brasil do século XIX, dadas as mudanças no modo de viver da classe burguesa no final do milênio. Ambas as autoras remetem ao colonialismo e ao pós-colonialismo, a primeiro analisando a sociedade brasileira e a segundo as relações de poder do primeiro mundo em relação ao terceiro mundo. Para a associação com a obra, foi observada a constante inferiorização e dependência das personagens mulheres em relação aos homens, comportamento este que é fruto de uma sociedade patriarcal escravocrata. Dada a relevância do tema e a permanência do comportamento observado, os estudos e discussões sobre a temática tornam-se cada vez mais importantes.

PALAVRAS-CHAVE: $O$ mulato; Condição feminina; Sociedade patriarcal; Inferiorização; Poder.

ABSTRACT: This present article aims to analyze the female condition in the novel. We opted for the bibliographical survey of works with a historical approach, with emphasis on those works of Brazilian author Mary Del Priore, the Indian theorist Gayatri Spivak and the book cited above, by Aluísio Azevedo. Both theories refer to colonialism and post-colonialism, the first depicting Brazilian society and the second, the power relations of the first world in relation to the third world. What make us reflect about the treatment and condition given to women, taking account the changes in the way of life of the bourgeois class in Brazil and in the rest of the world. For the association with the literary work, we observe constant inferiorization and dependence of the female characters in relation to the men, behavior that is the fruit of a patriarchal slave society. Given the relevance of the theme and the permanence of observed behavior, the studies and discussions on the theme become increasingly important.

KEYWORDS: $O$ mulato; Female condition; Patriarchal society; Inferiorization; Power.

\section{INTRODUÇÃO}

O século XIX foi um período de significativas mudanças no Brasil. O país saía de um cenário de produção majoritariamente agrícola, ao passo que fazia seus primeiros contatos com a economia capitalista. A vinda da família real ocasionou mudanças na organização das cidades - inicialmente no Rio de Janeiro e com o passar do tempo alcançaram outras localidades, que

\footnotetext{
${ }^{1}$ Discente do curso de Letras - Língua e Literatura Portuguesa pela Universidade Federal do Amazonas-UFAM. Email: taleessragine1@gmail.com

${ }^{2}$ Discente do curso de Letras - Língua e Literatura Portuguesa pela Universidade Federal do Amazonas-UFAM.

3 Professora Assistente na Universidade Federal do Amazonas (UFAM), mestra em Letras - Estudos Literários pela Universidade Federal do Amazonas (UFAM). Doutorado em andamento em Teoria e História Literária pela Universidade Estadual de Campinas (UNICAMP), com financiamento da Fundação de Amparo à Pesquisa do Amazonas (FAPEAM).
} 
passavam a usufruir de modernidades, como energia a gás. Apesar dos avanços, o sistema escravocrata ainda persistia sob forte domínio do regime do patriarcado. Não somente os escravizados eram regidos por este sistema, mas toda a sociedade. Homens brancos conduziam suas famílias e negócios, como se pode ler na pintura realista “Arrufos” (Figura1).

Figura 1 - Tela de Belmiro de Almeida (Arrufos, 1887)

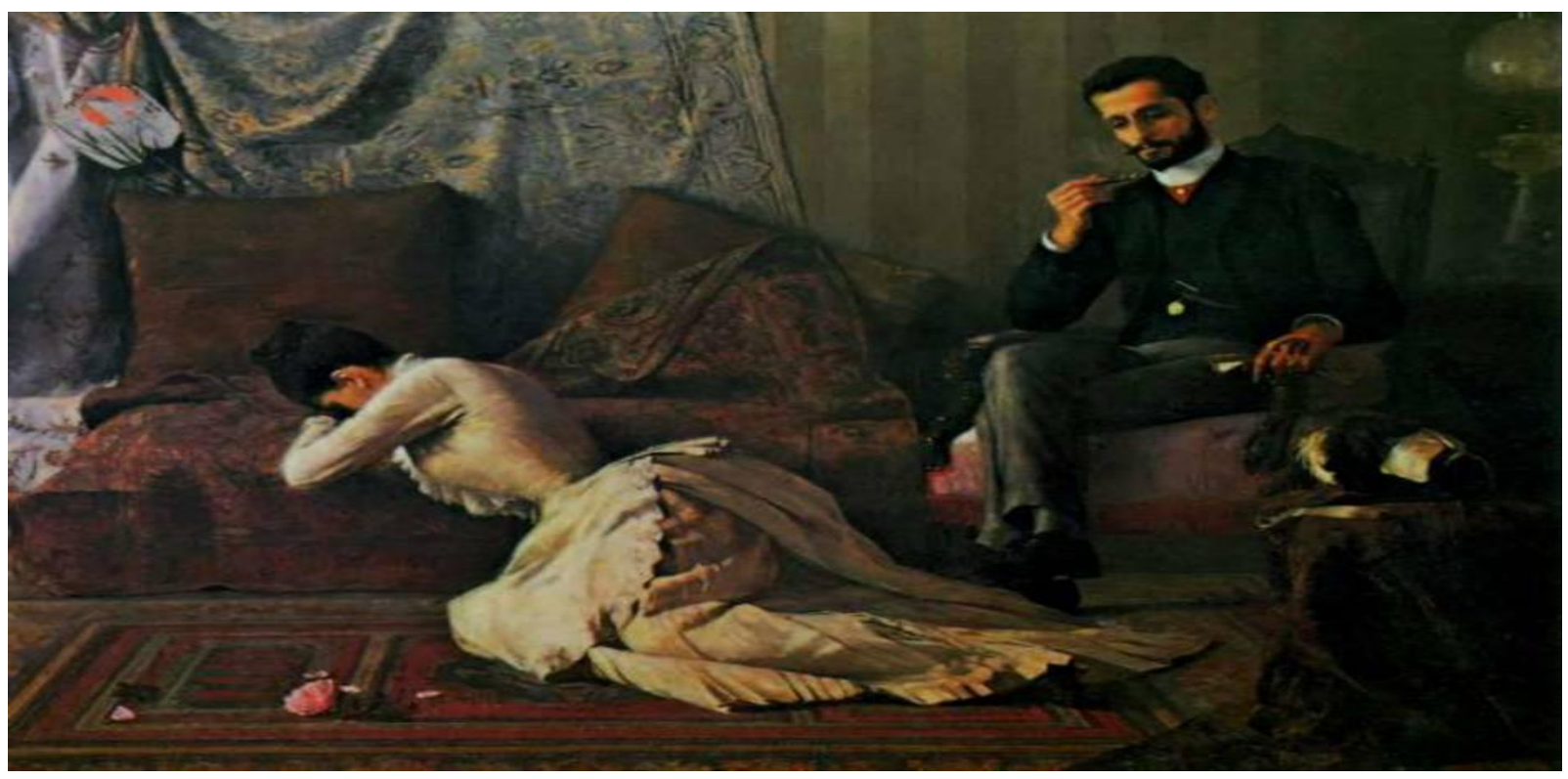

Fonte: Enciclopédia Itaú virtual, 2015.

Ganhadora do prêmio da Exposição Geral de Belas Artes no ano de 1890, a tela pintada em 1887 por Belmiro de Almeida, pode ser interpretada como um registro dos comportamentos comuns no século XIX. Iniciando pelo nome do quadro, que sugere o conteúdo da tela. De acordo com o dicionário Aurélio (1999), Arrufo é um desentendimento e consequente ressentimento entre pessoas que se gostam, como evidenciam os signos retratados na tela. $\mathrm{O}$ casal encontra-se na alcova da residência, lugar descrito da seguinte forma por Maria D'Incão: “As alcovas, espaço do segredo e da individualidade, forneciam toda a privacidade necessária para a explosão dos sentimentos: lágrimas de dor ou de ciúmes, saudades, declarações amorosas (...)" (2001, p. 229). A mulher aparenta ter passado recentemente por uma dessas explosões de sentimentos, visto a disposição do seu corpo no ambiente. Podemos observar as cores utilizadas por Belmiro de Almeida, em que a clareza do vestido da figura feminina contrapõe-se às cores das vestes masculinas, imprimindo a ele um ar de objetividade, sobriedade e controle em oposição às cores a aos objetos que estão próximos à mulher, como as cortinas e lençóis mal arrumados e as flores jogadas ao chão. Chama atenção as posições diferentes: o homem, em situação mais elevada, mostra-se indiferente em relação às emoções da mulher, que está no 
chão, próxima aos pés dele; o ato de fumar revela tranquilidade e ou indiferença; a mulher, por sua vez, é retratada num posicionamento que pode ser interpretado como de "estar em desespero", em situação de desequilíbrio emocional, cedendo ao choro. Desta forma, a imagem geral passada pela obra é da racionalidade do homem e do sentimentalismo da mulher, sendo esta primeira característica mais estimada socialmente.

Tal como é retratado nesta obra, a mulher do século XIX era vista pelos homens como inferior, e sua capacidade se limitava às atividades ligadas ao casamento - serviços domésticos, criação dos filhos e zelo pela imagem (física e moral) do marido diante da sociedade. Essa imagem de inferioridade da mulher fez com que fosse arraigada uma cultura de dependência do homem, de forma que a figura masculina, constituída de respeito, equilíbrio e inteligência, fosse indispensável a uma possível estabilidade da mulher.

No livro O Mulato (2010), cujo enredo é constituído por personagens femininas de distintas classes sociais, níveis culturais, etnias, condição financeira e tipos físicos, é possível observar que estas estão sob a condição de dominação masculina. Esta análise, no entanto, opta por examinar majoritariamente a mulher branca, que, apesar de fazer parte do círculo social burguês, não goza de liberdade em relação aos homens. Um pequeno número tem acesso aos estudos e a alguma expressão cultural, o que não influencia em sua ascensão social, permanecendo encarregadas do espaço familiar, das atividades religiosas e de outras atividades, como a costura, artesanato, organização de festas, bailes e funerais. Nenhuma exerce uma profissão de prestígio. Todas vivem sob o sustento de um homem.

O que se propõe neste trabalho é analisar os aspectos acerca da mulher apresentados nas personagens de $O$ Mulato (2010), citadas acima, à luz dos aportes teóricos (dentre outros), a saber: História das mulheres no Brasil (2001) e A mulher na História do Brasil (1994), o primeiro organizado e o segundo escrito pela professora Mary Del Priore ${ }^{4}$, que analisa em suas publicações a condição da mulher na sociedade burguesa e o tratamento dado às mesmas.

\section{O BRASIL DO SÉCULO DO SÉCULO XIX}

Os estudos acerca da posição da mulher na sociedade contemplam, evidentemente, outras épocas e lugares além do século XIX no Brasil. A ideia de "superioridade do homem" atravessa gerações e culturas e não deixa de acompanhar as naus de Portugal; as práticas dos portugueses com indígenas são largamente conhecidas, assim como com as escravas no início da

\footnotetext{
${ }^{4}$ Pós-doutorada na Ecole Des Hautes Etitudes Em Sciencies Sociales de Paris. Ex-professora de História da USP e da PUC/RJ. (Informação obtida em: http://marydelpriore.com.br/)
} 
colonização. No entanto, este trabalho, para efeito de organização, deter-se-á somente no intervalo de tempo relativo ao enredo de $O$ mulato.

Os costumes sociais comuns no Brasil do século XIX são, em sua maioria, importados da Europa, as ideias liberais se propagavam - ainda que a escravidão fosse uma contradição, havia um status em ser semelhante aos europeus, "Em resumo, as ideias liberais não se podiam praticar, sendo ao mesmo tempo indescartáveis" (SCHWARTZ, 2000, p. 26), além das ideias, alguns comportamentos também passaram a ser adotados, como aponta Schwartz:

A transformação atendia à mudança dos costumes, que incluíam agora o uso de objetos mais refinados, de cristais, louças e porcelanas, e formas de comportamento cerimonial, como maneiras formais de servir à mesa. (2000, p.23)

Da Europa veio também, com a colonização, o modelo de sociedade patriarcal e escravocrata, cujo poder emanava da figura masculina. Além desta, também havia intensa influência exercida pela Igreja Católica - que não deixa de ser um ambiente majoritariamente masculino, com concentração da autoridade nas mãos de homens, que ditavam o que deveria ser feito. A interferência dos padres na vida pessoal dos casais acontecia por meio do aconselhamento, já que os religiosos sempre desfrutaram da confiança e respeito dos patriarcas. As mulheres confessavam-se e ouviam passivamente o que orientavam os representantes da Igreja. Além do aconselhamento individual e da exposição nos sermões, Del Priore (1994) registra que foram elaborados livros de aconselhamento com o fim de doutrinar os casais. Entre eles está o livro Instrução às senhoras casadas para viverem em paz e quietação com seu marido, escrito pelo Frei Manuel de Arceniaga em 1782. ${ }^{5}$

Antes de adentrar propriamente na temática do casamento, é necessário comentar a formação intelectual - ou a falta dela, das moças. Segundo Louis Agassiz (1938, apud MONTEIRO, 1981, p.87), o nível de instrução era pouco, as mulheres não recebiam conhecimento que ultrapassasse as poucas noções de história e de religião do Brasil, seu tempo de permanência nos pensionatos era curto e insuficiente para adquirir o conhecimento considerado satisfatório. Além disso, nos raros casos em que uma delas frequentava ensino superior, devia estar acompanhada dos pais ou responsáveis, além de enfrentar problemas burocráticos:

5 Frei na Província de São José. Autor ascético. (Informação obtida em: <http://users.bart.nl/ roestb/franciscan/franautm.htm\#ManueldeArceniega>). 
As mulheres não tinham acesso ao ensino superior, mesmo as oriundas de famílias ricas, exceto os raríssimos casos de algumas que conseguiram a concessão para prosseguir os estudos, mas tudo baseado em uma série de documentos enviados às academias e apresentação de atestado de boa conduta. (CUNHA, 2010, p. 4)

E Agassiz (1938, p. 87), completa: "Em suma, além do círculo estreito de sua existência doméstica, nada existe para ela". Sem perspectivas acadêmicas, o que geraria uma possível independência financeira, todos os "esforços" eram concentrados na busca de um cônjuge. Gerava-se uma expectativa na moça, de modo que esta acreditava que alcançava sua plenitude e cumpria seu propósito ao selar o voto do casamento. Havia uma organização, manter a moça em casa, vigiar seus raros passeios, toda essa proteção exagerada tinha como fim não permitir o relacionamento da filha com um pretendente que não fosse o visado por seu pai, como afirma D’Incão: "Essa rigidez pode ser vista como o único mecanismo existente para a manutenção do sistema de casamento, que envolvia a um só tempo aliança política e econômica" (2001, p. 235). Ainda sobre a negociação do casamento, um elemento fundamental para a elevação do "valor" da mulher era a virgindade, novamente vejamos o que afirma D’Incão: “Independentemente de ter sido ou não praticada como um valor ético propriamente dito, a virgindade funcionava como um dispositivo para manter o status da noiva como objeto de valor econômico e político" (2001, p. 235). Se os matrimônios eram organizados visando bens e status, já é de se deduzir o afirmado por Del Priore "Na documentação desse período, mais e mais o historiador encontra elementos que atestam a ausência de amor" (2006, p. 163). Cabe observar que a fase individual (solteira) da mulher não deveria durar muito tempo, e esse período não era caracterizado pela liberdade da infância, as meninas não tinham as mesmas brincadeiras que os meninos nos quintais; aos onze anos já lhe era exigido bom comportamento e aos treze passava a usar roupas de mulheres adultas, com rendas e decotes (FREYRE, 1961). Tudo era precoce, de acordo com Monteiro (1994, p. 88), aos 20 anos e sem casar, a moça já era tida como "solteirona".

Depois de finalmente casar, a moça, que dantes já não gozava de liberdade, agora vive em verdadeiro cárcere. Gilberto Freyre (1960, p. 810) afirma: “[...] a mulher do Brasil é mantida sob uma reserva extrema, em uma clausura que era outrora quase absoluta”. Essa clausura era prejudicial não somente para o emocional, mas a saúde física das mulheres também era afetada, a carência dos mais simples exercícios físicos as deixava fracas e debilitadas, sendo vitimadas facilmente por doenças como a tuberculose (FREYRE, 1960). Os lugares frequentados por elas eram poucos, sendo um dos mais comuns a igreja, como afirma Priore "O evento social mais importante continuava a ser a missa dominical" (2006, p. 125), lá podiam, de maneira 
extremamente discreta, encontrarem-se. Não somente iam à igreja como se dedicavam intensamente às atividades religiosas.

Partem de representantes da igreja algumas falas sobre o comportamento a ser adotado pelas mulheres, como o de Lopes Gama ${ }^{6}$ (1842), citado por Freyre (2013, p. 141):

Para o padre-mestre, a boa mãe de família não devia preocupar-se senão com a administração de sua casa, levantando-se cedo a fim de dar andamento no serviço, partir a lenha, se fazer o fogo na cozinha, se matar a galinha mais gorda para a canja (...).

Isso não quer dizer que a sociedade laica pensasse de forma distinta, como mostra a fala de um juiz, citado por Mary Del Priore (1994, p. 17): "Fazendo a mulher o que é contrário de amar e respeitar o seu marido é permitido a este reger e aconselhar sua mulher, e ainda castigá-la moderadamente se merece". À mulher estavam reservadas as responsabilidades de cuidar do lar e procriar, o que permite pensar sobre a condição de viúvas e estéreis que, impossibilitadas de exercerem tais papéis, eram duplamente negligenciadas.

Intelectualmente excluídas, sentimentalmente feridas, sexualmente exploradas, as mulheres do século XIX, responsáveis pela boa ordem da família, e consequentemente da sociedade, tiveram sua contribuição apagada pela figura masculina. Infelizmente, o comportamento observado no século XIX pouco mudou ao longo dos dois séculos que o sucederam, e o que foi proferido por um anônimo, citado por Del Priore (1994, p.20), ainda povoa a mentalidade do século XXI: "É o homem quem deve mandar e a mulher criada para obedecer".

\section{PERSONAGENS FEMININAS: DA OBRA À REALIDADE}

Um preâmbulo se faz necessário antes de adentrar na obra literária de Aluísio Tancredo Gonçalves de Azevedo. Nasceu no Maranhão em 14 de abril de 1857, iniciando os seus estudos em pintura na Escola de Belas Artes. Trabalhou com o ensino de português, criação de desenhos e caricaturas para o jornal da época até lançar sua obra $O$ Mulato, no ano de 1881. A obra literária revoluciona a escrita, até então romantizada, no Brasil, mostrando ao público de leitores maranhenses facetas de uma sociedade patriarcal, com resquícios do colonialismo, enraizada nos preconceitos. Aluísio Azevedo recebeu várias críticas após a publicação do livro, principalmente das autoridades maranhenses, incluindo também as autoridades religiosas. $\mathrm{O}$ autor critica

\footnotetext{
${ }^{6}$ Manuel do Sacramento Lopes Gama (1971-1852), também conhecido como Padre Carapuceiro foi jornalista, religioso e político brasileiro; atuou na Bahia e Pernambuco. Foi professor de Retórica e eleito deputado em 1946.
} 
veementemente a hipocrisia da alta classe burguesa maranhense, expondo o racismo, a exploração infantil, a dissimulação por parte dos padres e clérigos, que pregavam os bons costumes e não seguiam os mesmos, e a dependência e inferiorização das mulheres, tema sobre o qual este artigo se debruça.

A obra naturalista de Aluísio Azevedo retrata, de modo fictício, a maneira a qual eram tratadas as mulheres, fossem elas brancas ou negras. No romance, a filha de Manuel Pescada, Ana Rosa, desde pequena almeja o casamento e somente nele vê uma forma de ser feliz. O pai, dono de comércios e apólices, é viúvo e cuida da moça, juntamente com a avó, Maria Bárbara. No fragmento do livro, vemos o quanto a moça necessita e pensa sobre o matrimônio, de tal maneira, que chega a adoecer, como se observa no fragmento:

\begin{abstract}
Sim, precisava casar, fazer família, ter um marido, um homem só dela, que a amasse vigorosamente!" E via-se dona-de-casa, com o molho das chaves na cintura - a ralhar, a zelar pelos interesses do casal, cheia de obrigações, a evitar o que contrariasse o esposo, a dar as suas ordens para que ele encontrasse o jantar pronto. E queria fazer-lhe todas as vontades, todos os caprichos tornar-se passiva, servi-lo como uma escrava amorosa, dócil, fraca, que confessa sua fraqueza, seus medos, sua covardia, satisfeita de achar-se inferior ao seu homem [...] (AZEVEDO, 2010, p. 108).
\end{abstract}

No excerto observamos nitidamente que Ana Rosa tinha todas suas expectativas de vida voltadas ao casamento e, consequentemente, aos deveres como esposa, mãe e dona do lar. Mariana, mãe de Ana Rosa, só aparece na trama devido às lembranças da filha, pois a mesma já havia morrido. Mariana dizia à filha que somente deveria se casar com um homem que amasse, visto que a mesma havia tido um matrimônio construído por interesses e status, evidenciado o casamento arranjado daquela época.

As três mulheres citadas até o momento são sustentadas e vivem sob a guarda de Manuel Pescada. A filha vive enclausurada no ambiente familiar, vigiada incessantemente pela avó e pelo cônego Diogo. D. Maria Bárbara passa a morar com o sogro e a neta, devido à morte da filha e também por já ser ela viúva. No fragmento, a senhora lembra-se do marido com certa estima: “Lembrava-se com grandes suspiros do marido 'do seu João Hipólito' um português fino, de olhos azuis e cabelos louros" (AZEVEDO, 2010, p. 23).

Ana Rosa, além dos cuidados da avó, tem também de Mônica, chamada de "mãe pretinha" pela moça, visto que a escrava foi sua ama de leite, cuidando de Ana Rosa como filha já que os seus próprios filhos foram vendidos para o Sul.

Além destas, observamos outras típicas personagens femininas da sociedade patriarcal. Maria do Carmo, uma senhora viúva, vive com duas sobrinhas, chamadas de "as irmãs Sarmento". Maria do Carmo lembra-se a todo o momento do falecido marido: "— Ai, o meu 
rico tenente! Lamentava-se ela quando alguém lhe lembrava o esposo. Que maneiras de homem! Que coração de pomba! Aquilo é que era um marido como hoje em dia não se vê!." (AZEVEDO, 2010, p. 68). Seu único passatempo, junto com as sobrinhas, é acompanhar a vida dos conhecidos e ir às festas e aos bailes. As sobrinhas, Etelvina e Bernardina (Bibina), são descritas como feias, somente reconhecidas pelos longos e volumosos cabelos. As moças não são casadas, tampouco estimadas pelos rapazes que procuram um possível compromisso, talvez um casamento.

Lindoca, amiga das Sarmento e de Ana Rosa, é filha do S. Freitas; retratada na obra como uma moça gorda, porém de feições agradáveis. Ela conhece um rapaz chamado Dudu Costa e nutrem interesse um pelo outro. Freitas vê no namoro o possível casamento, visto que o rapaz conseguiria uma nomeação na Alfândega, porém diz a si mesmo que o único problema é a "gordura de Lindoca": "Diabo era só aquela maldita gordura da menina, que aumentava todos os dias e estava fazendo dela um odre!" (AZEVEDO, 2010, p. 205).

Eufrazinha, a outra viúva, um pouco mais nova, lembra com grande apreço seu marido e sempre que pode conta a história de seu amado e como o mesmo havia morrido na Guerra do Paraguai. Relata que só foi completamente feliz na presença do marido, no casamento, que durou apenas dez dias e dez noites. A viúva Eufrazinha, no fim do romance, é vista como louca pelo fato de ter fugido com um moço mais jovem que ela.

Amância Sousellas, uma senhora que passa o tempo nas casas de parentes e amigos, não é casada e "cronicamente virgem" (2010, p. 68). Ao contrário das outras mulheres que perderam seus maridos, Amância, na "falta" de um cônjuge se ocupa dos comentários que faz sobre as famílias tradicionais, ou não, da sociedade maranhense. Tal comportamento atribuído à Amância gera repulsa nos pais, devido comentários obscenos. Apesar disso, é vista como uma mulher bem-humorada pelos jovens:

Mas a especialidade de D. Amância Sousellas, o que a tornava adorável para certos rapazes e detestada por muitos pais de família que iam de nariz torcido lhe recebendo visitas e obséquios de cortesia, era, sem dúvida, o seu antigo hábito de contar anedotas baixas e grosseiras. Sempre fora muito desbocada; no entanto alguns basbaques da sua roda, diziam dela, num frouxo de riso: "Com a D. Amância não pode a gente estar séria! - $\mathrm{O}$ diabo da velha tem uma graça!... (AZEVEDO, 2010, p. 69)

Angelina, filha do caseiro, que aparece brevemente no romance é vista por Raimundo na antiga fazenda de José da Silva. Aquele, por sua vez, faz uma pequena objeção ao vê-la, uma moça de dezoito anos, boa dona de casa e "boa para procriar": "Era mulher de dezoito anos; 
mulher, porque tinha já o corpo em plena formatura - ombros fartos, colo cheio e braços desenvolvidos no trabalho ao ar livre: ‘Boa mulher para procriar!...' pensou ele (2010, p. 171).

É interessante observar que o modo como as personagens são tratadas independe de sua idade, status de relacionamento ou condição financeira. Tudo parece insuficiente para elevar o valor da mulher e lhe conceder algum reconhecimento. Aparentemente, o fato de os homens serem considerados superiores às mulheres, era visto como uma condição biológica, como exemplificado no excerto em que Ana Rosa pensa sobre a condição da mulher:

Não! Ela não podia admitir o celibato, principalmente para a mulher!... "Para o homem - ainda passava... viveria triste, só; mas em todo o caso - era um homem... teria outras distrações! Mas uma pobre mulher, que melhor futuro poderia ambicionar que o casamento?" (AZEVEDO, 2010, p. 27)

Reforçando a ideia abordada no corpus do trabalho, a mulher, tanto na realidade quanto na ficção, é postulada, muita das vezes, como o sexo frágil e dócil. Este pensamento também posto pela crítica e teórica Gayatri Chakravorty Spivak, em Pode o subalterno falar? (2010), revela as condições dos subalternos em relação aos grupos dominantes, como, por exemplo, os estrangeiros. Na escala dos subalternos, Spivak lista mulheres (em primeiro lugar), prisioneiros, soldados recrutados, os pacientes de hospitais e os homossexuais (2010, p. 69) numa espécie de dominados pelo sistema colonial e imperialista do primeiro mundo.

Observamos na obra de Aluísio Azevedo uma sociedade maranhense do final do século XIX que ainda se encontra num sistema totalmente enraizado nas relações de poder do patriarcado, em que as mulheres são silenciadas. Spivak, em sua obra, frisa: se, no contexto da produção colonial, o sujeito subalterno não tem história e não pode falar, o sujeito subalterno feminino está ainda mais profundamente na obscuridade (2010, p. 67).

Baseando-se na condição do subalterno feminino na sociedade indiana, Spivak revela as divergências culturais; se no Brasil as mulheres são silenciadas, na Índia não é diferente, dada a realidade do sistema de castas e a herança colonial.

No caso anterior, uma imagem da "mulher" está em questão - uma imagem cuja predicação mínima como algo indeterminado já está disponível para a tradição falocêntrica. A historiografia subalterna traz à tona questões de método que a impediram de usar tal artifício. Com respeito à "imagem" da mulher, a relação entre mulher e silêncio pode ser assinalada pelas próprias mulheres, as diferenças de raça e de classe estão incluídas nessa acusação. (SPIVAK, 2010, p. 66) 
O termo empregado pela teórica para exprimir a ideia da superiodade masculina, "tradição falocêntrica", revela este centro dominador, tanto de poder quanto no próprio aparelho reprodutor masculino. As mulheres são subjugadas não só pelas condições e etnia, mas também pelo gênero. Em O Mulato (2010), mulheres brancas e negras, ricas e pobres são subjugadas e silenciadas. Ana Rosa não pode manifestar opinião quando o pai, Manuel Pescada, impõe o matrimônio com Dias, recusando-se a aceitar o amor da filha pelo primo Raimundo (negro). A ama de leite, Mônica, vê-se presa à Ana Rosa, não somente pelo amor cultivado, mas também pelo sistema escravocrata.

O duplo silêncio observado nas personagens remete à obra de Spivak, em que fala: Ao buscar aprender a falar (em vez de ouvir ou falar em nome do) sujeito historicamente umedecido pela mulher subalterna, o intelectual pós-colonialista sistematicamente "desaprende" o privilégio feminino (2010, p.88). Esse silenciamento duplo é percebido na personagem Domingas, mãe de Raimundo, que, na condição de escrava e mulher, é desvalorizada e maltratada por todo um sistema.

Em todas as personagens femininas, podemos observar a inferiorização e até ridicularização, seja por condições físicas e aparência, ou a dependência criada pelo homem, que sempre se coloca como alguém superior, subjugando as mulheres às suas vontades. A mulher é limitada por discursos ligados a fatores biológicos e emocionais, vista como "boa para procriar" ou "louca" e até mesmo "ridícula". O pensamento que se tem sobre as mulheres, como Mary Del Priore cita em seu livro, é de que elas deveriam ser doces, submissas, bonitas, agradáveis e nunca contrariar a decisão ou opinião do marido; se esse preceito não é seguido, é inferiorizada pela sociedade patriarcal.

A partir da análise do contexto histórico e da obra, pode-se inferir que $O$ Mulato (2010) captura a realidade do século XIX e insere na composição de suas personagens, em especial as personagens femininas. O narrador encarrega-se de descrever o cotidiano das mulheres e homens, inserindo na trama ficcional críticas à sociedade maranhense, neste caso, críticas ao machismo; entende-se que a sociedade maranhense representa toda a sociedade brasileira.

\section{REFERÊNCIAS}

AGASSIZ, Luiz;AGASSIZ, Elizabeth Cary apud PESSOA, Marília Monteiro. A posição da mulher no Brasil do século XIX. In: Revista do Programa de Pós-Graduação em História da Universidade Federal de Pernambuco, Pernambuco, n.04, p.88,1981. 
ARRUFOS. In: ENCICLOPÉDIA Itaú Cultural de Arte e Cultura Brasileiras. São Paulo: Itaú Cultural, 2018. Disponível em: <http://enciclopedia.itaucultural.org.br/obra6374/arrufos>. Acesso em 26 de Fev. 2018.

AZEVEDO, Aluísio. O mulato. 2. ed. São Paulo: Martin Claret, 2010.

CUNHA, Washington Dener dos Santos Cunha; SILVA, Rosemaria J. Vieira. Gênero. In: Revista do Núcleo Transdisciplinar de Estudos de Gênero (NUTEG) do Programa de Estudos Pós-Graduados em Política Social (UERJ-Universidade do Estado do Rio de Janeiro), Rio de Janeiro, n. 11, p. 97, 2010.

D'INCÃO. Maria Ângela. Mulher e família burguesa. In: PRIORE, Mary Del (org). História das Mulheres no Brasil. São Paulo: Contexto,2001. pp. 223-240.

DEL PRIORE, Mary. A História das mulheres no Brasil. 5. ed. São Paulo: Contexto, 2001.

DEL PRIORE, Mary. A História do Amor no Brasil. 2. ed. São Paulo: Contexto, 2006.

DEL PRIORE, Mary. A mulher na história do Brasil. 4ª ed. São Paulo: Contexto, 1994

FERREIRA, Aurélio Buarque de Holanda. Novo Aurélio Século XXI: o dicionário da língua portuguesa. 3. ed. Rio de Janeiro: Nova Fronteira,1999.

FREYRE, Gilberto. Sobrados e Mucambos. São Paulo: Global, 2013.

MONTEIRO, Marília Pessoa. A posição da mulher no Brasil do século XIX. In: Clio - Revista do Programa de Pós-Graduação em História da Universidade Federal de Pernambuco, Pernambuco, n. 04, p. 88, 1981.

SCHWARZ, Roberto. As ideias fora do lugar. IN Ao vencedor as batatas: forma literária e processo social nos inícios do romance brasileiro. São Paulo: Duas Cidades, 2000. pp. 11-31.

SPIVAK, Gayatri Chakravorty. Pode o subalterno falar? Trad. Sandra Regina Goulart Almeida; Marcos Pereira Feitosa; André Pereira. Belo Horizonte: Editora da UFMG, 2010.

Recebido em: 28/02/2018

Aprovado em: 01/04/2018

Publicado em: 01/07/2018 